\title{
Long-Term Persistence of Antibody Response with Two Doses of Inactivated Hepatitis A Vaccine in Children
}

\author{
Ashish Agrawal (1) - Shafi Kolhapure (1) - Anar Andani (1) · \\ Martin O. C. Ota (1) - Selim Badur (1) - Naveen Karkada (1) · \\ Monjori Mitra
}

Received: May 14, 2020

(C) The Author(s) 2020

\section{ABSTRACT}

Introduction: Hepatitis A virus infection is more severe in adults than children. Although

Digital Features This article is published with digital features, including a summary slide, graphical plain language summary and video, to facilitate understanding of the article. To view digital features for this article go to https://doi.org/10.6084/m9.figshare. 12472760 .

Supplementary Information The online version supplementary material available at https://doi.org/10. 1007/s40121-020-00311-8.

A. Agrawal ( $\square)$

Medical Affairs Department, GSK, Hyderabad, India

e-mail: ashish.8.agrawal@gsk.com

S. Kolhapure

Medical Affairs Department, GSK, Mumbai, India

A. Andani

Global Medical Affairs, GSK, Wavre, Belgium

M. O. C. Ota

Vaccines Scientific Affairs and Public Health, GSK,

Wavre, Belgium

S. Badur

Vaccines Scientific Affairs and Public Health, GSK, Istanbul, Turkey

N. Karkada

Clinical Research \& Development, GSK, Wavre, Belgium

M. Mitra

Medclin Research Pvt, Kolkata, India vaccination can protect adults, current childhood programs cover a large population more successfully. Childhood vaccination is, therefore, a solution to protecting adults if it induces lasting immunity. Fifteen-year protection has been demonstrated in children, but longer-term data are only available for adults. We aimed to predict long term persistence of antibody in children beyond 15 years and assess if immunological mechanisms triggered by vaccination support longer-term protection.

Methods: Long-term clinical studies using hepatitis A (HAV) or A/B vaccines (HAB) containing 720 or 1440 Enzyme-linked immunosorbent assay Units (EU) of hepatitis A virus antigen were identified. Duration of persistence of antibodies and possible protection was determined by descriptively comparing antibody geometric mean concentration (GMC) kinetics, as well as GMC (95\% confidence interval) at 15 years postvaccination across studies. Immunological mechanism studies describing hepatitis A vaccination were identified.

Results: One study in children $12-15$ years (2dose HAB 720) and four in adults (2-dose HAV 1440 and 3-dose HAB 720) showed comparable GMC kinetics and per year rates of change up to 15 years. At 15 years, the GMC in children $[414.7 \mathrm{mEU} / \mathrm{ml}(336.9 ; 510.5)]$ was in the same range as in adults [range $282.6(217.6 ; 367.0)$ to 550.1 (416.0; 727.4)]. Based on these data, mathematical model predictions from adult studies (showing $>85 \%$ protected at 50 years) 
were deemed likely to also apply to children. Studies identified, both humoral and cell-mediated responses are induced following vaccination.

Conclusion: Based on comparable antibody data in adults and children up to 15 years, similar longer-term antibody persistence is expected in children with 2-dose inactivated hepatitis A 720 containing vaccine at least up to 50 years. Accordingly, improving routine childhood hepatitis A vaccination coverage could protect against more severe disease in adulthood.

Trial Registration: ClinicalTrials.gov identifiers, NCT00875485, NCT01000324, NCT01037114, NCT00289757, NCT00291876.

Long-Term Persistence of Antibody Response with Two Doses of Inactivated Hepatitis A Vaccine in Children Ashish Agrawal, Shafi Kolhapure, Anar Andani, Martin O.C. Ota, Selim Badur, Naveen Karkada, Monjori Mitra
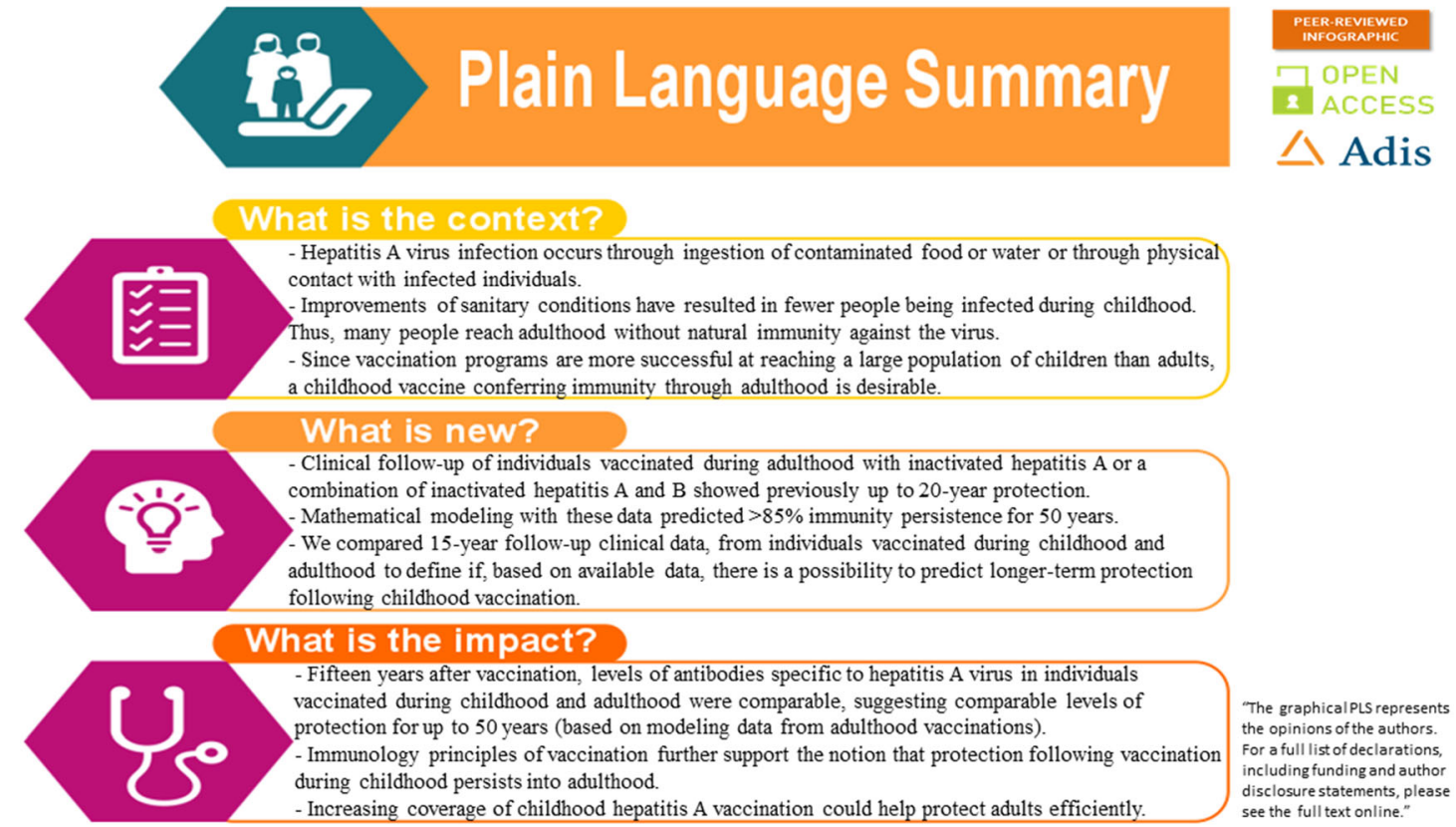

Fig. 1 Plain language summary

Keywords: Children; Inactivated hepatitis A vaccine; Long-term persistence

\section{Key Summary Points}

\section{Why carry out this study?}

With shifting endemicity in some areas, the risk of having asymptomatic hepatitis A in childhood is reduced and there is a greater risk of more severe hepatitis A disease in adulthood. 
As there is no treatment, prevention through vaccination is the best option. Vaccination programs are currently more successful at reaching a larger population of children than adults. Therefore, childhood vaccination that triggers immunity lasting into adulthood could provide the solution.

Childhood hepatitis A vaccination has demonstrated protection up to 15 years, but longer-term protection data are available from studies in adults.

\section{What was learned from the study?}

This study compared long-term immune responses to hepatitis $A$ vaccination in adults and children up to 15 years in order to predict duration of long-term protection following childhood vaccination.

Based on the descriptive comparison of antibody data, childhood vaccination with two doses of hepatitis A 720 containing vaccine induced antibodies that could persist at least up to 50 years and is therefore likely to provide protection into adulthood. Thus, increasing coverage of routine childhood hepatitis A vaccination is a useful tool to protect against high disease burden in adults.

\section{INTRODUCTION}

The Global Burden of Disease Study 2013 identified viral hepatitis as an increasing leading cause of death (10th in 1990 to 7th in 2013). Worldwide, viral hepatitis deaths increased by $63 \%$ and disability-adjusted life-years by $34 \%$ from 1990 to 2013, with most of the burden in east and south Asia. While age-specific rates tended to decline, the absolute burden of disease increased due to population growth and changing age structures. With the availability of effective vaccines and other non-pharmaceuti- cal measures, much can still be done to improve public health [1]. Although hepatitis $\mathrm{A}$ is a vaccine-preventable disease, its incidence increased by $4.2 \%$ between 2005 and 2015, to 114.2 million cases worldwide [2].

Hepatitis A virus infection is typically asymptomatic and self-limiting in children, but age is a risk factor, and more severe symptoms are common in older age groups who can take months to recover, with important societal and economic knock-on effects in affected communities. In parts of the world, hepatitis A endemicity is changing due to improved sanitary conditions, with fewer people being infected in childhood and thus reaching adulthood naïve to hepatitis $A$ and at risk of more severe infection from epidemics. Improved sanitation, access to clean water, food hygiene and vaccination remain the most effective strategies to protect against this virus, and of utmost importance since no treatment option is available to date [3].

Across the globe, countries with routine hepatitis A mass vaccination programs have been successful in targeting children and achieving high coverage. Awareness in adolescents and adults, however, is low, even though they are at higher risk of more complicated severe disease if not immunised earlier in life. Vaccination in childhood, therefore, provides an opportunity for protection against hepatitis $A$ in adulthood, providing the induced immune response lasts long enough [4]. Several welltolerated, highly immunogenic and effective hepatitis A inactivated vaccines from GSK are available in various doses [360, 720 or 1440 enzyme-linked immunosorbent assay units (EU) of inactivated hepatitis A viral antigen] and schedules ( 2 or 3 doses), administered as a monovalent hepatitis A vaccine (HAV) or combination hepatitis $A$ and $B$ vaccine (HAB). The safety and immunogenicity of combined hepatitis $A$ and $B$ vaccine are comparable to those of the respective monovalent vaccines [5-7].

Long-term protection with inactivated vaccine has been demonstrated in follow-up studies of clinical trials in adults (17 years and older) $[8,9]$. Long-term antibody persistence data in 
children has not been as widely studied. A study in Alaska comparing three-dose HAV 360 EU in various schedules in children aged 3-6 years found that, after 20 years follow-up, $88.5 \%$ had protective antibody concentrations, with modelling predicting protective levels at 30 years [10]. A study in China in children aged 1-8 years found that, after 11 years follow-up, the seroprotection rate was $100 \%$ with two doses HAV $720 \mathrm{EU}$, and modelling predicted that the duration of protection was at least 30 years [11]. A study comparing two doses HAB 720 EU (adult dose) with three doses HAB 360 EU (paediatric dose) in children aged 12-15 years found that $100 \%$ of subjects in both groups remained protected against hepatitis $\mathrm{A}$ and $\mathrm{B}$ after 15 years [12]. There is a need to further demonstrate the longevity of the immune response, but longer-term data are not available to date, and such long-term studies are costly and challenging to conduct. However, it may be possible to use existing data to predict longerterm outcomes. In the studies above, for example, mathematical modelling was used successfully to not only confirm the 20-year outcomes observed in the adult studies but also to predict longer-term protection outcomes in children and adult studies [8-11].

Vaccines can elicit humoral immunity (B cell/antibody response) as well as cell-mediated immunity ( $\mathrm{T}$ cell response). The nature of the vaccine determines the resulting type of immune response. $\mathrm{T}$ cell-dependent responses can be elicited by toxoid, protein, and inactivated or live-attenuated viral vaccines, and they induce higher-affinity antibodies as well as immune memory. Long-term protection from vaccination requires maintenance of antibody concentrations above a given protective threshold and/or maintenance of immune memory cells that reactivate following subsequent exposure to the virus [13].

The objective of this study was to descriptively compare the immune response observed with the children versus adult hepatitis A dosing schedules, and, if comparable, to extrapolate the duration of antibody persistence in children based on existing long-term data in adults.

\section{METHODS}

\section{Identification of Studies with Long-Term Immunogenicity Data}

To minimise external factors that could bias our findings, the descriptive analysis focussed only on GSK vaccines that are formulated using the same technology and for which long-term data are available.

A search of the GSK clinical studies (available from https://www.gsk-studyregister.com/en/) identified clinical studies of vaccines containing inactivated hepatitis A antigen, either as standalone HAV (Havrix; GSK, Belgium) or combination HAB (Twinrix; GSK, Belgium). Studies with at least 10 years of follow-up of antibody persistence data were included, as well as any longer-term follow-up of these studies using mathematical modelling $[8,9]$. In order to extrapolate outcomes in children using data in adults, studies with data on adult vaccine doses of HAB $720 \mathrm{EU}$ or HAV $1440 \mathrm{EU}$ were selected. The group of subjects in the children study given paediatric doses of HAB $360 \mathrm{EU}$ [12] was excluded as this dose is not used in clinical practice. Children were defined as anyone aged under 18 years old, as the recommended inactivated vaccination dose and schedule is the same for this age group.

All procedures in the studies involving human participants were performed in accordance with the Good Clinical Practice Guidelines, as defined by the International Conference on Harmonization, the Declaration of Helsinki and its later amendments or comparable ethical standards.

\section{Investigating Comparability of Antibody Kinetics Across Dosing Schedules}

Anti-hepatitis A antibody geometric mean concentrations (GMC, in $\mathrm{mEU} / \mathrm{ml}$ ) were calculated at various timepoints in each study (e.g. months and years since vaccination). The GMCs and the fold change in GMC (i.e. per year rate of GMC change, calculated as previous year GMC/current year GMC) were plotted by year since vaccination for each study. The first fold change is 
therefore computed by considering the GMC 1 month post-last dose (that is after dose 2 or 3 ) as previous year GMC. The kinetics in the plotted GMC curves and change curves over time for each study (and, by extension, for each dosage schedule) were descriptively compared, in order to extrapolate the longer-term antibody kinetics following two doses of HAB 720 EU in children.

\section{Extrapolating Long-Term Persistence}

Mathematical models have previously been published $[8,9]$ to confirm the long-term outcomes collected in studies on three doses of HAB $720 \mathrm{EU}$ and two doses of HAV $1440 \mathrm{EU}$, as well as to predict longer-term outcomes with these vaccines from the individual patient data collected. In these studies, a linear-mixed model was used to predict long-term seropositivity rates after vaccination. The models were fitted with the individual trial population observed long-term immunogenicity data. The mean trend for observed antibody levels and calculation of the coefficient of simple determination $\left(R^{2}\right)$ and the D index of agreement were based on Hens et al. [14]. Data from subjects who received a booster dose or with obvious outliers (e.g. abnormal rise in titres following vaccination) were excluded from the model [8]. The proportion of seropositive subjects was estimated, and uncertainty assessed using nonparametric bootstrapping to obtain 95\% confidence intervals. The Akaike Information Criterion was used for model selection. Goodness of fit was assessed using standard diagnostic tools for linear mixed models.

If the comparison of GMC data (described above) show kinetics similar in adults and children, the long-term antibody persistence in children with two doses of HAB 720 EU could be predicted, using the longer-term mathematical modelling results from adult data. If, at the 15-year follow-up, the GMC from the study in children is in the same range as the GMC intervals from adult studies, then longer-term predictions of the percent of seropositive subjects will be made for children based on longerterm model predictions for adults.

Figure 1 elaborates on the findings in a form that can be shared with patients by healthcare professionals.

\section{Compliance with Ethics Guidelines}

This article is based on previously conducted studies and does not contain any studies performed by any of the authors with human participants or animals.

\section{RESULTS}

The search in the GSK database identified five studies with over 10 years of clinical data on vaccine containing hepatitis A antigen (Table 1)

Table 1 Demographic characteristics of the subjects (TVC cohort)

\begin{tabular}{|c|c|c|c|c|c|}
\hline \multirow{3}{*}{$\begin{array}{l}\text { Dosage } \\
\text { Study name } \\
\text { NCT }\end{array}$} & \multirow{3}{*}{$\begin{array}{l}2 \times \text { HAB } 720 \\
\text { HAB-084 } \\
00875485\end{array}$} & \multicolumn{2}{|c|}{$3 \times$ НАВ 720} & \multicolumn{2}{|c|}{$2 \times$ HAV 1440} \\
\hline & & HAB-028 & HAB-032 & HAV-112 & HAV-123 \\
\hline & & 01000324 & 01037114 & 00291876 & 0028975 \\
\hline Countries & Belgium, Czech Republic & Belgium & Belgium & Belgium & Belgium \\
\hline Schedule, months & 0,6 & $0,1,6$ & $0,1,6$ & 0,12 & 0,6 \\
\hline N Total & 150 & 150 & 156 & 220 & 151 \\
\hline Males, \% & 47.3 & 18.0 & 19.2 & 27.3 & 48.3 \\
\hline Mean age, years $\pm S D$ & $13.4 \pm 1.07$ & $19.6 \pm 2.85$ & $21.7 \pm 5.54$ & $22.3 \pm 3.47$ & $31.4 \pm 5.91$ \\
\hline
\end{tabular}

$H A B$ combination hepatitis $\mathrm{A}$ and $\mathrm{B}$ virus vaccine, $H A V$ hepatitis A virus vaccine, $N$ number of subjects, $N C T$ clinical trial number identifier at www.clinicaltrials.gov, $S D$ standard deviation, $T V C$ total vaccinated cohort 
(NCT00875485, NCT01000324, NCT01037114, NCT00289757, and NCT00291876; www. clinicaltrials.gov): one study in children (two doses HAB $720 \mathrm{EU}$ ) with 15 years of clinical follow-up data [12], four studies in adults (three doses HAB 720 EU [9], and two doses HAV 1440 EU $[8,15,16])$ with up to 20 years of clinical follow-up. The adult studies also had longerterm immunogenicity data based on mathematical modelling predictions $[8,9]$. The demographic details of the groups included in this descriptive analysis are presented in Table 1.

\section{Comparison of Antibody Persistence Across Different Dose Schedules}

At 1-month post-schedule completion, GMC $(\mathrm{mEU} / \mathrm{ml})$ was 5313.5 (children 2-dose HAB 720); 6200.0 and 4620.1 (adult 3-dose HAB 720 studies); and 5243.0 and 3462.7 (adult 2-dose HAV 1440 studies). The GMCs remained over the protective threshold level of $20 \mathrm{mEU} / \mathrm{mL}$ until the end of the follow-up period across all studies in children and adults.
Figure 2 shows the anti-hepatitis A antibody GMC, by study and dose schedule, at each follow-up after primary vaccination. Higher and comparable GMCs 18-months post-completion of vaccination schedule are observed in all studies in children and adults. Across all studies, the GMC decrease over time follows a comparable trend and does not appear to differ significantly in the children study versus adult studies.

Figure 3 shows the fold change in antibody GMCs over time by study. There is an initial rapid decrease in GMC in the first years following vaccination, after which the rate of change per year reached a plateau that persisted until the end of each study's follow-up period. The pattern for rate of change in antibody GMC appears to be very similar across children and adult studies and dosage schedules, and antibody GMCs appear to remain relatively constant in the long term.

Based on the similarities observed in Figs. 2 and 3 across children and adult studies with their respective dosing schedules, it appears very likely that the GMCs in the children dosing

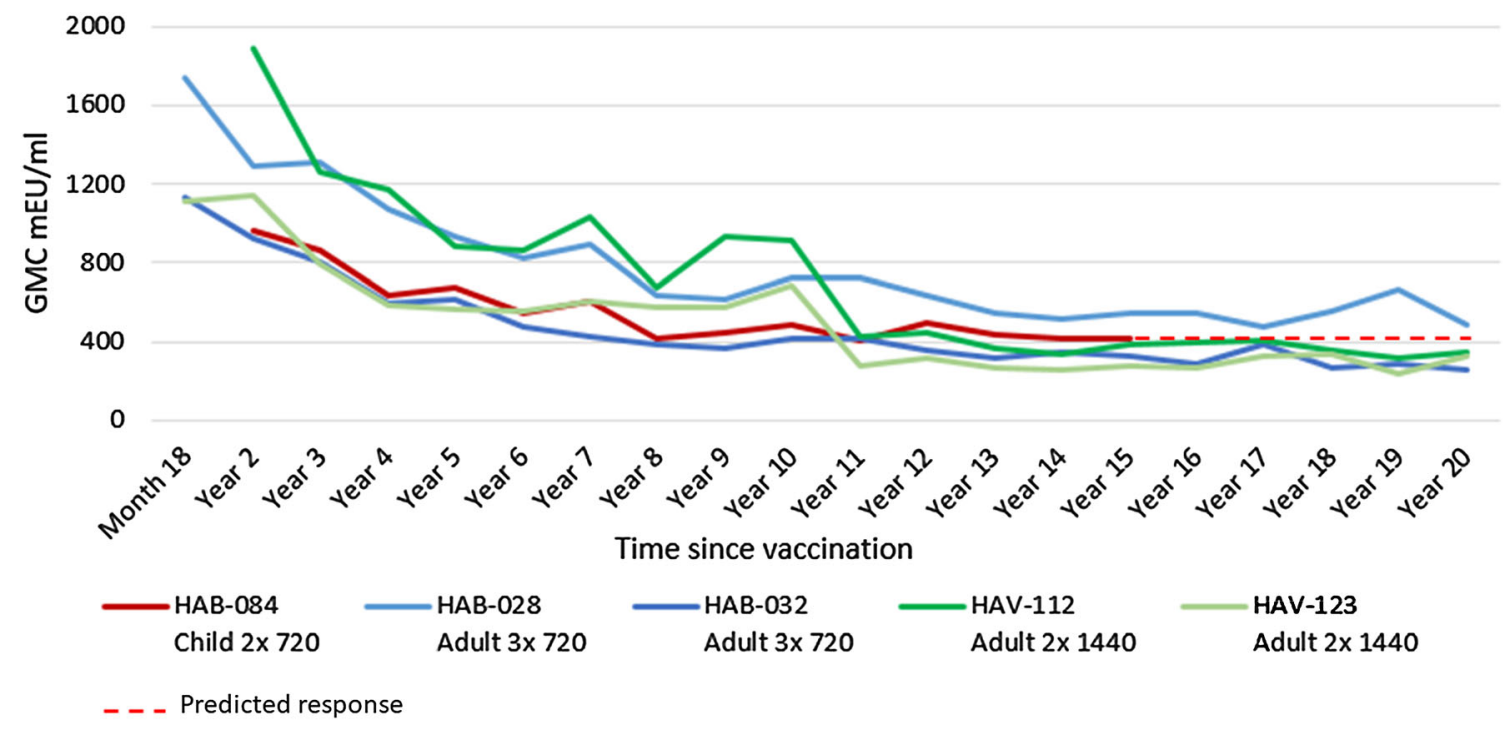

Fig. 2 Antibody geometric mean concentration by study (TVC cohort). There was a change in the assay used during follow-up (year 6 and year 11 for 3-dose and 2-dose adult studies, respectively). The cut-off used in the new assay differed, as seen by the peak in the graphs for these years. $G M C$ geometric mean concentration, $E U$ enzymelinked immunosorbent assay units, $H A B$ combination hepatitis $\mathrm{A}$ and $\mathrm{B}$ virus vaccine, $H A V$ hepatitis $\mathrm{A}$ virus vaccine, $T V C$ total vaccinated cohort 

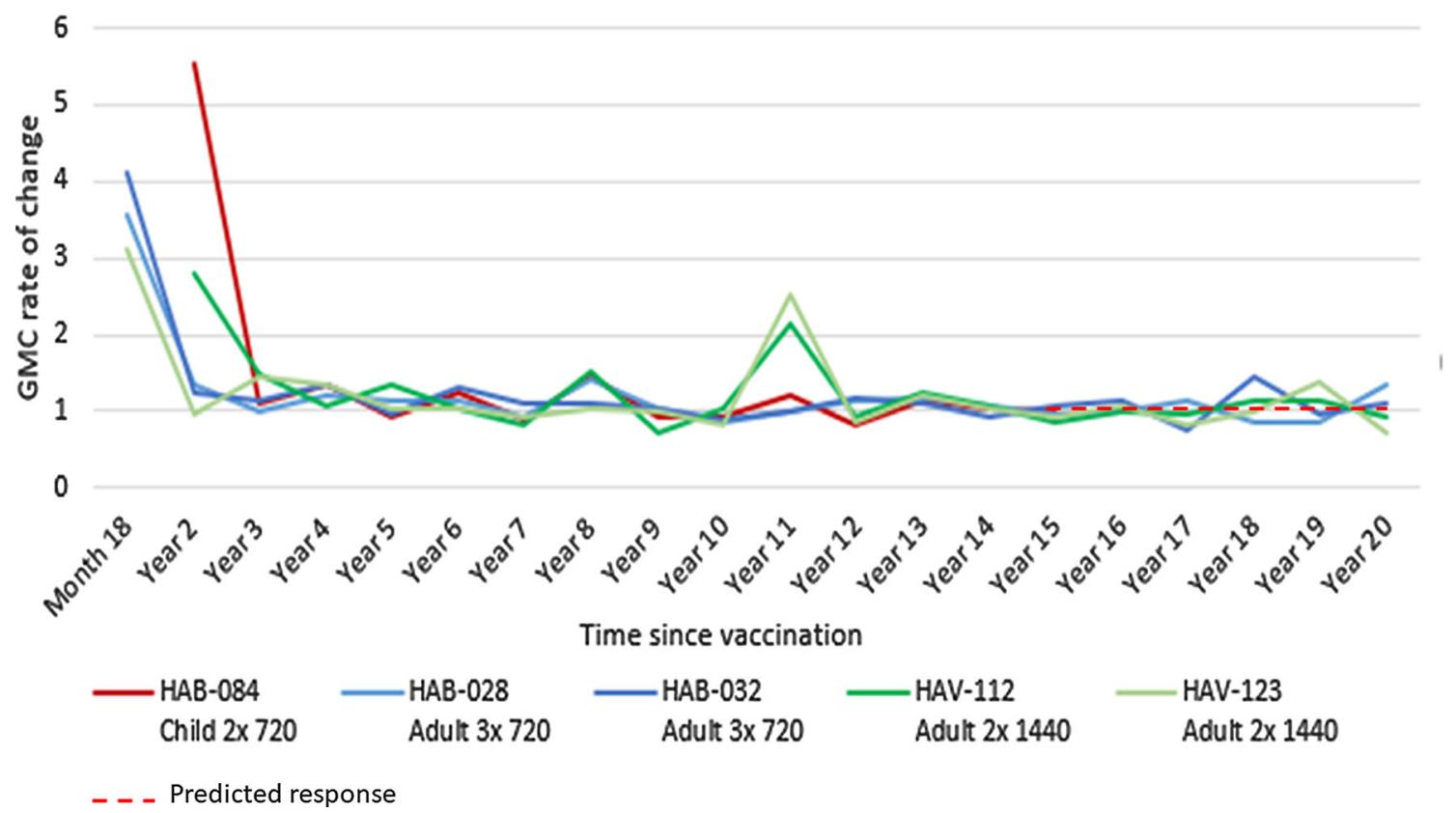

Fig. 3 Antibody geometric mean concentration fold change by study (TVC cohort). There was a change in the assay used during follow-up (year 6 and year 11 for 3-dose and 2-dose adult studies, respectively). The cut-off used in the new assay differed, as seen by the peak in the

schedule would follow the same kinetics after 15 years as in the adult studies.

\section{Estimation of Persistence Based on Mathematical Modelling Data}

Mathematical modelling was previously applied to the adult study data to predict longer-term persistence beyond 20 years. The models predicted that over $90 \%$ and over $85 \%$ of subjects would remain seropositive at year 40 and year 50, respectively, following 2-dose HAV 1440 EU vaccination [8]. Similarly, over $97 \%$ of subjects were predicted to remain seropositive at year 40 following 3-dose HAB $720 \mathrm{EU}$ vaccination [9].

Table 2 shows the adult and children study data (GMC and 95\% confidence intervals; CI) and model predictions at several timepoints post vaccination. Based on 15-year follow-up data, GMCs varied between 282.6 and $550.1 \mathrm{mEU} / \mathrm{ml}$ for adult studies. The children study GMC point estimate (414.7) appears to be comparable to two adult studies (i.e. fits within graphs for these years. $G M C$ geometric mean concentration (enzyme-linked immunosorbent assay units), $H A B$ combination hepatitis $\mathrm{A}$ and $\mathrm{B}$ virus vaccine, $H A V$ hepatitis A virus vaccine, $T V C$ total vaccinated cohort

the 95\% CI): a 3-dose HAB 720 and a 2-dose HAV 1440, and appears to fit in between the other two studies which had the highest and lowest GMC, respectively. Based on these findings and the similar kinetic trends above (Fig. 2, $3)$, it is likely that a mathematical model predicting longer-term outcomes for the children study would also predict findings at least comparable to the lower predictions made for the 2-dose HAV 1440 studies, namely $>85 \%$ remain protected after 50 years.

\section{DISCUSSION}

Vaccination remains a key means to prevent hepatitis A disease [3]. Childhood vaccination offering long-term protection provides a means to protect children as they grow into adolescents and adults, who are difficult to vaccinate in large numbers. With current practice, it is easier to vaccinate children, but moving forward a trend towards vaccinating adolescents 
Table 2 Antibody geometric mean concentrations (95\% CI) and model predicted \% seropositive

\begin{tabular}{|c|c|c|c|c|c|}
\hline Dosage & $2 \times$ НАВ 720 & $3 \times$ НАВ 720 & & $2 \times$ HAV 1440 & \\
\hline Study name & HAB-084 & HAB-028 & HAB-032 & HAV-112 & HAV-123 \\
\hline NCT & 00875485 & 01000324 & 01037114 & 00291876 & 00289757 \\
\hline \multicolumn{6}{|c|}{1 month post-schedule completion } \\
\hline$n$ & 148 & 128 & 152 & 165 & 102 \\
\hline GMC (95\% CI) & $\begin{array}{l}5313.5 \\
(4488.8 ; 6289.8)\end{array}$ & $\begin{array}{l}6200.0 \\
(5449.0 ; 7055.0)\end{array}$ & $\begin{array}{l}4620.1 \\
(4056.5 ; 5262.1)\end{array}$ & $\begin{array}{l}5243.0 \\
(4441.5 ; 6189.0)\end{array}$ & $\begin{array}{l}3462.7 \\
(2941.5 ; 4076.2)\end{array}$ \\
\hline \multicolumn{6}{|l|}{15 years follow-up } \\
\hline$n$ & 98 & 50 & 51 & $128^{\mathrm{a}}$ & 62 \\
\hline GMC (95\% CI) & $\begin{array}{l}414.7 \\
(336.9 ; 510.5)\end{array}$ & $\begin{array}{l}550.1 \\
(416.0 ; 727.4)\end{array}$ & $\begin{array}{l}326.9 \\
(244.7 ; 436.8)\end{array}$ & $\begin{array}{l}389.9 \\
(323.4 ; 470.0)\end{array}$ & $\begin{array}{l}282.6 \\
(217.6 ; 367.0)\end{array}$ \\
\hline \multicolumn{6}{|l|}{20 years follow-up } \\
\hline$n$ & - & 28 & 44 & $114^{\mathrm{b}}$ & 47 \\
\hline GMC (95\% CI) & - & $\begin{array}{l}487.9 \\
(339.6 ; 701.0)\end{array}$ & $\begin{array}{l}257.3 \\
(188.6 ; 351.0)\end{array}$ & $\begin{array}{l}345.0 \\
(278.6 ; 427.3)\end{array}$ & $\begin{array}{l}330.7 \\
(248.7 ; 439.7)\end{array}$ \\
\hline \multicolumn{6}{|l|}{ Model predicted } \\
\hline$\%$ seropositive 40 years & - & $>97 \%$ & & $>90 \%$ & \\
\hline$\%$ seropositive 50 years & - & - & & $>85 \%$ & \\
\hline
\end{tabular}

$G M C$ geometric mean antibody concentration, $H A B$ combination hepatitis $\mathrm{A}$ and $\mathrm{B}$ virus vaccine, $H A V$ hepatitis $\mathrm{A}$ virus vaccine, $n$ number of subjects with available results, $C I$ Confidence interval

a 15.5 years

b 20.5 years

and adults as part of healthy ageing would be welcomed. A long-term childhood vaccination study with inactivated hepatitis A vaccine showed $100 \%$ of subjects remained protected at 15 years follow-up after 2 doses of HAB $720 \mathrm{EU}$ [10]. Long-term data from children in Argentina vaccinated with another 2-dose inactivated hepatitis A vaccine also found good long-term persistence, as $97.9 \%$ of children at the 10 -year follow-up still had protective concentrations of hepatitis A antibody [17]. However, longer-term data beyond this are needed.

We found that antibody GMC trends from the study in children were comparable to those from studies in adults that used 3-dose HAB 720 EU and 2-dose HAV 1440 EU with 20-year follow-up and up to 50-year model-predicted outcomes. Based on the very similar GMC outcomes and 15-year trends across these studies, we conclude that childhood vaccination is likely to provide comparable longer-term protection that will extend to adulthood.

Both humoral and cell-mediated immune responses are induced after one dose of vaccine, and can be boosted after receiving a second dose, with cell-mediated immunity providing long-term protection regardless of decreasing antibody levels. The GMC trends over time showed that antibody levels tend to decline faster initially, which could be due to shortlived plasma cells. However, after a certain period, antibody GMC decline slows, due to long lived plasma cells that continue to produce antigen-specific antibodies [18]. This suggests 
that, even if antibody titres decline over time, vaccinated individuals coming into contact with hepatitis A virus will be able to mount an appropriate immune response as a result of a deposit of memory immune cells.

\section{Immunological Mechanisms for Long- Term Immunity Persistence with Hepatitis A Vaccine}

Detectable antibody levels of $10-33 \mathrm{EU} / \mathrm{ml}$, depending on the assay, are used to indicate protection from hepatitis A infection. However, from clinical experience, vaccine-induced protection may exist, even in the absence of detectable anti-hepatitis A antibodies [19], which is usually due to the cell-mediated immune response.

A World Health Organization review (2011) reported evidence of inactivated hepatitis A vaccination leading to an important and longlasting cell-mediated immune response that can be boosted, in addition to its rapid effective humoral response. The response was seen within 2 weeks of vaccination, reaching a peak after 1 month, followed by a subsequent decline in T cells and B cells; this decline could be reversed, with a booster dose at week 24 following the primary vaccination, leading to a significant increase in humoral and cell-mediated immunity [20].

Evidence from long-term follow-up clinical studies and mathematical models have shown that humoral responses to hepatitis A vaccination lasts for decades, with second dose resulting in rapid proliferation of memory B cells and high antibody titres. In studies where a challenge dose was administered $15-20$ years after primary immunisation with HAB 720 [9] and HAV $1440[8,16]$, subjects mounted a strong anamnestic response indicating the presence of immune memory.

The evidence supporting the role of vaccineinduced cell-mediated immunity, through cytokines and T-helper cells, was based on documented interferon (IFN) gamma secretion [21, 22], IFN gamma and interleukin (IL)-10 production by peripheral blood lymphocytes 10 days after vaccination [23], and observation of a direct correlation between cytokine concentrations (IL-2, IFN gamma and IL-10) and anti-hepatitis A antibody levels before and after booster vaccination [24]. In one study, peripheral blood mononuclear cells were observed in $100 \%$ of vaccinees 1 month after a single dose of HAV $1440 \mathrm{EU}$, and the subsequent 60\% decline of cellular immune responses by week 12 was reversed after a 6-month booster dose producing an over sevenfold increased response compared to that following primary vaccination [25].

The main limitations of this study relate to the methodology of extrapolating data to ascertain long-term persistence of immunity in children instead of doing the actual follow-up for that period. It was not possible to carry out a long-term study (this would have taken decades in real time). The only study in children in the analysis had a mean age of 13.4 years. Similar long-term persistence would, however, be expected in younger children vaccinated with inactivated hepatitis A vaccine. A non-GSK study in children in China (mean age 3.7 years) found that after 11 years of follow-up, all children vaccinated with two doses of HAV 720 remained seroprotected [11].

Despite these limitations, hepatitis A studies worldwide show that the vaccine is highly immunogenic, has long-term persistence and has been successful in disease control. A national two-dose hepatitis A toddler program started in 1999 in Israel, and has had a positive long-term impact with significant incidence declines in all age groups: overall, a 95\% decline after 3 years [26] and a 98\% decline after 9 years [27] was observed in annual incidence compared with the pre-vaccination period.

\section{CONCLUSIONS}

Our study suggests that existing long-term data in children would follow the same trends as the adult data, providing high levels of protection likely to last several decades, at least up to 50 years. Therefore, greater efforts are needed to improve hepatitis A vaccine coverage in routine childhood programs to prevent more severe and complicated disease later in life. 


\section{ACKNOWLEDGEMENTS}

Funding. GlaxoSmithKline Biologicals SA funded this research, all costs associated with its development and the Rapid Service Fees. All authors had full access to all of the data in this study and take complete responsibility for the integrity of the data and accuracy of the data analysis.

Authorship. All named authors meet the International Committee of Medical Journal Editors (ICMJE) criteria for authorship for this article, take responsibility for the integrity of the work as a whole, and have given their approval for this version to be published.

Medical Writing, Editorial, and Other Assistance. The authors thank Business \& Decision Life Sciences platform for editorial assistance and manuscript coordination, on behalf of GSK. Benjamin Lemaire coordinated publication development and editorial support. Kavi Littlewood (Littlewood Writing Solutions, Houten, The Netherlands) provided medical writing support. Editorial support and medical writing assistance were funded by GlaxoSmithKline Biologicals SA. The authors also wish to thank Dr. Archana Jastorff (Modis Life Sciences, c/o GSK) for assistance in conceptualization.

Disclosures. Ashish Agrawal is an employee of the GSK group of companies and declares no non-financial conflicts of interest. Shafi Kolhapure is an employee of the GSK group of companies, holds shares as part of his employee remuneration and declares no non-financial conflicts of interest. Anar Andani is an employee of the GSK group of companies, holds shares as part of her employee remuneration and declares no non-financial conflicts of interest. Martin O.C. Ota is an employee of the GSK group of companies, holds shares as part of his employee remuneration and declares no non-financial conflicts of interest. Selim Badur is an employee of the GSK group of companies and declares no non-financial conflicts of interest. Naveen Karkada is an employee of the
GSK group of companies, holds shares as part of his employee remuneration and declares no non-financial conflicts of interest. Monjori Mitra declares no financial and non-financial conflicts of interest.

Havrix and Twinrix are trademarks owned by or licensed to the GSK group of companies.

Compliance with Ethics Guidelines. This article is based on previously conducted studies and does not contain any studies performed by any of the authors with human participants or animals.

Data Availability. To request access to patient-level data and documents for this study, please submit an enquiry via www. clinicalstudydatarequest.com.

Open Access. This article is licensed under a Creative Commons Attribution-NonCommercial 4.0 International License, which permits any non-commercial use, sharing, adaptation, distribution and reproduction in any medium or format, as long as you give appropriate credit to the original author(s) and the source, provide a link to the Creative Commons licence, and indicate if changes were made. The images or other third party material in this article are included in the article's Creative Commons licence, unless indicated otherwise in a credit line to the material. If material is not included in the article's Creative Commons licence and your intended use is not permitted by statutory regulation or exceeds the permitted use, you will need to obtain permission directly from the copyright holder. To view a copy of this licence, visit http://creativecommons.org/licenses/by$\mathrm{nc} / 4.0 /$.

\section{REFERENCES}

1. Stanaway JD, Flaxman AD, Naghavi M, et al. The global burden of viral hepatitis from 1990 to 2013: findings from the Global Burden of Disease Study 2013. Lancet. 2016;388(10049):1081-8.

2. Global, regional, and national incidence, prevalence, and years lived with disability for 310 
diseases and injuries, 1990-2015: a systematic analysis for the Global Burden of Disease Study 2015. Lancet. 2016;388(10053):1545-602.

3. World Health Organization (WHO) Hepatitis A Key facts 2019. https://www.who.int/news-room/ fact-sheets/detail/hepatitis-a. Accessed 25-03-2020

4. Agrawal A, Singh S, Kolhapure S, Hoet B, Arankalle $\mathrm{V}$, Mitra M. Increasing burden of hepatitis a in adolescents and adults and the need for long-term protection: a review from the indian subcontinent. Infect Dis Ther. 2019;8(4):483-97.

5. Van Damme P, Van Herck K. A review of the efficacy, immunogenicity and tolerability of a combined hepatitis A and B vaccine. Expert Rev Vaccines. 2004;3(3):249-67.

6. Levie K, Beran J, Collard F, Nguyen C. Long term (24 months) follow-up of a hepatitis A and B vaccine, comparing a two and three dose schedule in adolescents aged 12-15 years. Vaccine. 2002;20(19-20):2579-84.

7. Thoelen S, Van Damme P, Leentvaar-Kuypers A, et al. The first combined vaccine against hepatitis A and B: an overview. Vaccine. 1999;17(13-14): $1657-62$.

8. Theeten H, Van Herck K, Van Der Meeren O, Crasta $P$, Van Damme P, Hens N. Long-term antibody persistence after vaccination with a 2-dose Havrix (inactivated hepatitis A vaccine): 20 years of observed data, and long-term model-based predictions. Vaccine. 2015;33(42):5723-7.

9. Van Damme P, Leroux-Roels G, Suryakiran P, Folschweiller N, Van Der Meeren O. Persistence of antibodies $20 \mathrm{y}$ after vaccination with a combined hepatitis A and B vaccine. Hum Vaccin Immunother. 2017;13(5):972-80.

10. Plumb ID, Bulkow LR, Bruce MG, et al. Persistence of antibody to Hepatitis A virus 20 years after receipt of Hepatitis A vaccine in Alaska. J Viral Hepat. 2017;24(7):608-12.

11. Wang Y, Qi Y, Xu W, et al. Immunogenicity persistence in children of hepatitis A vaccines Healive ${ }^{\circledR}$ and Havrix ${ }^{\circledR}$ : 11 years follow-up and long-term prediction. Hum Vaccin Immunother. 2020; https://doi.org/10.1080/21645515.2020.1715687.

12. Beran J, Van Der Meeren O, Leyssen M, D'Silva P. Immunity to hepatitis $\mathrm{A}$ and $\mathrm{B}$ persists for at least 15 years after immunisation of adolescents with a combined hepatitis $\mathrm{A}$ and $\mathrm{B}$ vaccine. Vaccine. 2016;34(24):2686-91.
13. Siegrist CA Vaccine Immunology. https://www. who.int/immunization/documents/Elsevier_ Vaccine_immunology.pdf. Accessed 02-04-2020

14. Hens N, Habteab Ghebretinsae A, Hardt K, Van Damme P, Van Herck K. Model based estimates of long-term persistence of inactivated hepatitis A vaccine-induced antibodies in adults. Vaccine. 2014;32(13):1507-13.

15. Van Damme P, Mathei C, Thoelen S, Meheus A, Safary A, Andre FE. Single dose inactivated hepatitis A vaccine: rationale and clinical assessment of the safety and immunogenicity. J Med Virol. $1994 ; 44(4): 435-41$.

16. Van Herck K, Crasta PD, Messier M, Hardt K, Van Damme P. Seventeen-year antibody persistence in adults primed with two doses of an inactivated hepatitis A vaccine. Hum Vaccin Immunother. 2012;8(3):323-7.

17. Lopez EL, Contrini MM, Mistchenko A, Debbag R. Long-term immunity after two doses of inactivated hepatitis A vaccine, in Argentinean children. Pediatr Infect Dis J. 2010;29(6):568-70.

18. Indian Academy of Pediatrics (IAP) IAP Guidebook on Immunization 2013-2014 2014. https://www. iapindia.org/wp-content/uploads/2018/07/IAPGuidebook-on-Immunization-2013-14.pdf. Accessed 03-04-2020

19. World Health Organization (WHO) WHO position paper on hepatitis A vaccines-June 2012. Wkly Epidemiol Rec. 2012;87(28/29):261-76.

20. World Health Organization (WHO) The Immunological Basis for Immunization Series Module 18: Hepatitis A 2011. https://apps.who.int/iris/handle/ 10665/44570. Accessed 02-04-2020

21. Cederna JB, Klinzman D, Stapleton JT. Hepatitis A virus-specific humoral and cellular immune responses following immunization with a formalininactivated hepatitis A vaccine. Vaccine. 1999;18(9-10):892-8.

22. Leroux-Roels G, Desombere I, Van Herck K, Thoelen S, Collard F, Van Damme P. Long-term persistence of cellular immunity towards hepatitis A virus following hepatitis A virus vaccination. In: Dienstag J, editor. Viral hepatitis and liver diseases. Proceedings of the 10th International Symposium on Viral Hepatitis and Liver Diseases; April 9-13, 2000; Atlanta, USA; Atlanta: International Medical Press; 2002. p. $41-44$.

23. Hayney MS, Buck JM, Muller D. Production of interferon-gamma and interleukin-10 after inactivated hepatitis A immunization. Pharmacotherapy. 2003;23(4):431-5. 
24. Garner-Spitzer E, Kundi M, Rendi-Wagner P, et al. Correlation between humoral and cellular immune responses and the expression of the hepatitis $A$ receptor HAVcr-1 on T cells after hepatitis A revaccination in high and low-responder vaccinees. Vaccine. 2009;27(2):197-204.

25. Schmidtke P, Habermehl P, Knuf M, Meyer CU, Sanger R, Zepp F. Cell mediated and antibody immune response to inactivated hepatitis A vaccine. Vaccine. 2005;23(44):5127-32.
26. Dagan R, Leventhal A, Anis E, Slater P, Ashur Y, Shouval D. Incidence of hepatitis A in Israel following universal immunization of toddlers. JAMA. 2005;294(2):202-10.

27. Levine H, Kopel E, Anis E, Givon-Lavi N, Dagan R. The impact of a national routine immunisation programme initiated in 1999 on Hepatitis A incidence in Israel, 1993 to 2012. Euro Surveill. 2015;20(7):3-10. 